This is a self-archived - parallel published version of this article in the publication archive of the University of Vaasa. It might differ from the original.

\title{
Expatriate work role engagement and the work- family interface: A conditional crossover and spillover perspective
}

Author(s): Reiche, B. Sebastian; Dimitrova, Mihaela; Westman, Mina; Chen, Shoshi; Wurtz, Olivier; Lazarova, Mila; Shaffer, Margaret A.

Title: Expatriate work role engagement and the work-family interface: A conditional crossover and spillover perspective

Year: $\quad 2021$

Version: Accepted version

Copyright (C)2021 Sage Publications. The article is protected by copyright and reuse is restricted to non-commercial and no derivative uses. Users may also download and save a local copy of an article accessed in an institutional repository for the user's personal reference.

\section{Please cite the original version:}

Reiche, B. S., Dimitrova, M., Westman, M., Chen, S., Wurtz, O., Lazarova, M., Shaffer, M.A. (2021). Expatriate work role engagement and the work-family interface: A conditional crossover and spillover perspective. Human Relations, o0187267211046816.

https://doi.org/10.1177/00187267211046816 


\section{Expatriate Work Role Engagement and the Work-Family Interface:}

\section{A Conditional Crossover and Spillover Perspective}

Reiche, B. Sebastian (IESE Business School); Dimitrova, Mihaela (Vienna University of Economics and Business); Westman, Mina (Tel Aviv University); Chen, Shoshi (Tel Aviv University); Wurtz, Olivier (University of Vaasa); Lazarova, Mila (Simon Fraser University); Shaffer, Margaret (University of Oklahoma)

\section{Corresponding Author:}

\section{B. Sebastian Reiche}

IESE Business School

Department of Managing People in Organizations

Ave. Pearson, 21

Barcelona 08034, Spain

E-mail: sreiche@,iese.edu

\section{Abstract}

How intertwined are expatriates with their families? And what makes some expatriates better than others at leveraging positive or compensating for negative influences from their family life? Drawing on conservation of resources, crossover and spillover theories, we examine when partner family role adjustment influences expatriates' family experiences, and how and when these experiences translate into expatriate work role engagement. Using data from 105 expatriate-partner dyads at two time points, we establish the key personal resource of general self-efficacy as a boundary condition for crossover and spillover. We find that expatriates with high self-efficacy experience no crossover between partner family role adjustment and expatriate family role adjustment, and positive spillover between their family role engagement and their work role engagement. By contrast, expatriates with low self-efficacy experience strong crossover between partner family role adjustment and expatriate family role adjustment, and negative spillover between their family role engagement and work role engagement. Our results suggest that the way in which the 
family domain influences expatriate work role engagement depends on general self-efficacy. We contribute to conservation of resources, crossover and spillover theories, and the workfamily interface during expatriation. Our results also pinpoint organizational interventions to improve expatriates' work role engagement.

Keywords: work engagement; crossover; spillover; conservation of resources theory; expatriates; general self-efficacy; family role adjustment; family role engagement 
"Sometimes only one person is missing and the whole world seems depopulated" Alphonse de Lamartine, 1820

As de Lamartine indicates, individuals are intertwined with others-both within and across life domains such as work and family (Bacharach et al., 2010; Powell et al., 2019). This is especially true for expatriates, defined as individuals who live and work in a foreign country for at least one year and intend to return to their home country rather than immigrate permanently (Tharenou, 2015). Industry surveys suggest that many expatriates relocate with their immediate family (e.g., Santa Fe Relocation, 2021). In particular, the geographical transitions the family unit experiences trigger significant changes. Expatriates encounter increased job responsibilities, excessive travel, and challenges of dealing with cultural others, which reduce the time and energy they can devote to family members. In the family, partners often experience the loss of their job, career and extended social support. In this challenging context, the boundaries between the work and family domains are more permeable and family members are more dependent on each other's support (Dimitrova, 2018; Lazarova et al., 2010; Shaffer and Harrison, 2001).

Not surprisingly, research has emphasized the critical role of expatriates' family life in influencing their work (Caligiuri et al., 1998; Lazarova et al., 2010). Notably, partners' adjustment is considered central for expatriate effectiveness (Bhaskar-Shrinivas et al., 2005), and is commonly assumed to directly and automatically transfer to the expatriate (Malek et al., 2015; Takeuchi et al., 2002). But how intertwined are expatriates with their families? When does the partner's adjustment influence the expatriate's experiences in the family sphere and how and when do these experiences translate to expatriates' work domain? It is possible that some expatriates are able to harness potentially positive and compensate for potentially negative influences from their family life better than others. However, we know little about whether and the extent to which specific attributes of the individual expatriate 
serve to channel family life influences into work outcomes.

Our aim is to better understand the dynamics and boundary conditions of how the family sphere influences expatriates' work life, specifically their work role engagement (i.e., high psychological presence and focus at work, Rothbard, 2001). We consider two theoretical processes that explicate this interface: crossover and spillover. Crossover is a dyadic process that concerns the transfer of experiences between two individuals (Westman, 2001). Spillover is a within-individual process whereby values, behaviors, and moods transfer between the family and the work roles for the same individual (Carlson et al., 2006). While existing crossover and spillover research has focused on partner-employee dyads in their home countries, our understanding of how individuals are affected by crossover and spillover in cross-border contexts is scarce (see Powell et al., 2019). The expatriation context serves as an extreme case to study (Eisenhardt, 1989) because both the focal employee and the partner encounter major life role transitions. This makes the resources that expatriates derive from their immediate social context more volatile, highlighting the critical role of personal resources. To advance our understanding, we draw on conservation of resources (COR) theory (Halbesleben et al., 2014; Hobfoll, 2001) to conceptualize expatriates' general selfefficacy —i.e., the cognitive appraisal of one's confidence to succeed (Bandura, 1997) — as a critical personal resource that conditions the transfer of family experiences to expatriates' work domain. Although both self-efficacy and the family domain have long been highlighted as central factors influencing the expatriate experience (Bhaskar-Shrinivas et al., 2005; Black et al., 1991; Caligiuri et al., 1998), they have rarely been studied jointly. This has limited our understanding of how expatriates' self-efficacy shapes their experiences at the intersection of work and family life.

Specifically, we study when the expatriate partner's adjustment to family life is a contextual resource for the expatriate (ten Brummelhuis and Bakker, 2012) that influences 
expatriates' family experiences (i.e., crossover), and how and when these experiences translate into expatriates' work role engagement (i.e., spillover). We propose a moderated mediation model (see Figure 1) that follows a sequence from affect to motivation (Lazarova et al., 2010) to integrate (1) the crossover from partner family role adjustment to expatriate family role adjustment, (2) the link between expatriate family role adjustment and expatriate family role engagement, and (3) the spillover from expatriate family role engagement to expatriate work role engagement. Importantly, we develop and test the idea that the key personal resource of expatriate general self-efficacy (Halbesleben et al., 2014; ten Brummelhuis and Bakker, 2012) is a boundary condition for both crossover and spillover.

\section{INSERT FIGURE 1 ABOUT HERE}

Our study makes several contributions. First, we advance COR theory by examining how personal and contextual resources interact and compensate for one another in the resource accumulation process during expatriation. Further, by conceptualizing the partner's family role adjustment as a contextual resource that captures the volatility inherent in the family domain during major role transitions, we help advance our understanding of COR theory explanations during personal and professional change more generally. Second, we demonstrate that expatriate general self-efficacy plays an important role in crossover and spillover processes. In doing so, we contribute to the broader research on spillover and crossover processes, which has largely neglected the role of moderators, especially more stable personality factors and cognitive constructs such as self-efficacy (Hobfoll et al., 2018; ten Brummelhuis and Bakker, 2012). Our findings suggest that individuals with low levels of self-efficacy will benefit from their partners' family role adjustment to successfully adjust to their own family role, while those with high self-efficacy can compensate for low levels of partner adjustment. We also integrate two contradictory propositions regarding whether 
individuals' engagement in the family may enrich or deplete their physical, emotional and cognitive reserves, and we demonstrate that the valence of spillover depends on self-efficacy. Third, by conceptualizing general self-efficacy as a boundary condition to crossover, we contribute to expatriate research that has assumed strong crossover in adjustment between the partner and the expatriate to be automatic (e.g., Takeuchi et al., 2002; Takeuchi, 2010). As such, our findings advance our understanding of how and when the family sphere influences the expatriate's work role engagement.

\section{Theoretical background}

We focus on expatriate work role engagement as our focal outcome variable for two reasons. First, engagement has been conceptualized as an intermediate variable linking affective constructs (e.g., adjustment) to behavior (e.g., performance), both in the work and family domains (Lazarova et al., 2010). As a motivational construct (Christian et al., 2011; Kahn, 1990), it should thus play a key role in linking two of the most frequently studied work outcomes in the expatriate literature, expatriate adjustment and performance (e.g., BhaskarShrinivas et al., 2005; Takeuchi, 2010). Second, expatriate research has begun to highlight the importance of motivational variables, including cross-cultural motivation (Chen et al., 2010) and goal orientation (Wang and Takeuchi, 2007), for various aspects of expatriate success. This is in line with broader research suggesting that work role engagement is a pivotal antecedent of work performance (Christian et al., 2011; Rofcanin et al., 2019). In this study, we adopt Rothbard's (2001) framework to conceptualize engagement as a twodimensional construct that includes attention (i.e., the duration of focus on and mental preoccupation with work and family) and absorption (i.e., the intensity of focus on the work and family roles). Consistent with Rothbard's conceptualization, we define expatriate role engagement as the degree to which expatriates have high psychological presence and focus when involved in their respective role activities. 
We are particularly interested in understanding when the partner's family role adjustment influences expatriates' experiences in the family sphere (crossover), and how and when these experiences translate to expatriates' work role engagement (spillover). Indeed, the expatriate literature suggests that the partner has a major influence on the expatriate's experience (e.g., Caligiuri et al., 1998; Malek et al., 2015; Shaffer and Harrison, 1998). To expand on previous literature, we follow recent studies that have started to illuminate the predictors and downstream consequences of crossover and spillover (e.g., Ferguson et al., 2015; Thompson et al., 2021). Initial evidence further suggests that there are boundary conditions to crossover and spillover. For example, Rofcanin et al. (2019) showed that subordinates' perceptions of family supportive supervisor behaviors strengthened the crossover of home engagement from supervisors to their subordinates. Similarly, research suggests that work-home segmentation preferences serve as a boundary condition for the spillover of workplace ostracism to the family domain (Liu et al., 2013).

\section{COR theory}

Central to understanding the crossover and spillover processes through which the family sphere influences expatriate work outcomes are the various resources that expatriates have at their disposal (Lazarova et al., 2010). Thus, we invoke COR theory (Halbesleben et al., 2014; Hobfoll, 2001) to better articulate these processes. COR theory is a motivational theory that explains human behavior based on the evolutionary need to protect current and obtain new resources (Hobfoll et al., 2018). The theory holds that individuals must invest resources to cope with the presence of stressors, which threaten existing resources, and that unsuccessful coping may lead to a spiral of resource loss.

COR theory categorizes resources based on their origin and their degree of transience (Hobfoll, 2002; ten Brummelhuis and Bakker, 2012). First, resources can be either located outside the self (i.e., contextual) or they can be proximate to the self like personal traits or 
energies (i.e., personal). Second, resources vary depending on whether they are transient and fleeting (i.e., volatile), or whether they are durable and stable (i.e., structural). Specifically, a partner's family role adjustment serves as a contextual resource for the expatriate. While the partner's family role adjustment may be stable in the short term, it can shift over time as the partner navigates the changes to the family domain while abroad, thus giving it a volatile nature.

COR theory also discusses the role of key personal resources (Halbesleben et al., 2014; Hobfoll, 2002). Unlike other resources, which may be finite and have more limited utility and scope (e.g., energy, skills, material and social support), key personal resources have far-reaching benefits and serve to unlock, enable, and maximize the use of other resources (Halbesleben et al., 2014; ten Brummelhuis and Bakker, 2012). They include certain personality traits (e.g., conscientiousness, emotional stability) and stable personal attributes (e.g., self-efficacy, emotional intelligence, optimism) that are versatile and durable enough to substitute other resources and facilitate the accumulation of new resources for attaining one's goals (Halbesleben et al., 2014). Key resources provide an explanation for why some individuals are better able than others to cope with stressful circumstances and accumulate new resources (ten Brummelhuis and Bakker, 2012). Due to their versatility and durability, key personal resources should be particularly salient when individuals encounter major role transitions, like during expatriation.

\section{General self-efficacy}

A key personal resource that should protect and grow expatriates' resource endowment abroad is self-efficacy. Here, we focus on general self-efficacy, which reflects a "belief in one's capabilities to organize and execute the course of action required to produce given attainments" (Bandura, 1997: 3). While self-efficacy is often treated as a domainspecific attribute that changes with the situation (e.g., Gist and Mitchell, 1992), in line with 
our COR theory perspective and the definition of key personal resources we are particularly interested in self-efficacy as an attribute that generalizes across tasks and situations.

There are two reasons for focusing on general self-efficacy in the expatriate context. First, self-efficacy has long been recognized theoretically and empirically as an important input to expatriate success (e.g., Black et al., 1991; Shaffer et al., 2016; Wu and BodigerelKoehler, 2013). Black and colleagues' (1991) model of expatriate adjustment, which has been the dominant theoretical foundation for an extensive body of research on expatriates, positions self-efficacy as an individual difference critical for adjustment — an assertion later supported in a meta-analysis by Bhaskar-Srinivas et al. (2005). Self-efficacy beliefs play a particularly central role during expatriation, as expatriates need to perform across a range of new situations, including new work roles, changed family dynamics and a novel host-country context (e.g., Shaffer et al., 2016). Navigating the far-reaching changes to all life domains due to relocation is easier when expatriates have the confidence to embrace the challenges and quickly bounce back from adversity. Indeed, self-efficacy captures differences in individuals' tendency to view themselves as capable of meeting different task and relational demands in a broad array of novel circumstances, persevere in the face of stressful and demanding situations (Bandura, 1986; Chen et al., 2001), succeed in attaining their goals (e.g., Phillips and Gully, 1997), and proactively shape their environment (Niessen et al., 2016; Parker et al., 2010).

Second, despite the recognized importance of self-efficacy for expatriate success, we know little about how it interacts with influences from the expatriates' family domain. We believe general self-efficacy is a critical boundary condition for crossover and spillover during expatriation. As a cognitive appraisal of one's confidence to succeed, self-efficacy complements the primary focus on affective and behavioral mechanisms through which work and life domains are thought to shape each other (Leslie et al., 2019; Neff et al., 2013). 
Further, it helps expand the primarily affective lens that expatriate scholars have adopted to study expatriate experiences (Haslberger et al., 2013). In short, we conceive expatriate general self-efficacy as a key personal resource that conditions the availability and use of expatriates' other resources and determines when and in which direction expatriates are more or less affected by crossover and spillover.

\section{Hypothesis development}

Crossover of affect: From partner family role adjustment to expatriate family role adjustment

Crossover is an interpersonal process through which negative and positive experiences and states experienced by one person are transmitted to another person in the same social environment (Bolger et al., 1989; Westman, 2001). To that end, research has provided evidence of crossover of burnout, anxiety, adjustment, satisfaction, engagement and happiness between partners (e.g., Carlson et al., 2019; Westman et al., 2009). Crossover has also been studied in the expatriation literature, with a focus on how the partner's adjustment crosses over to the expatriate's adjustment. This focus is not surprising considering that studies of antecedents to expatriate adjustment have dominated expatriation research (Takeuchi, 2010). Expatriate adjustment is most often defined as the “degree of a person's psychological comfort with various aspects of a new setting” (Black and Gregersen, 1991: 498).

Following this conceptualization, studies have provided clear evidence for crossover of adjustment between the partner and the expatriate (e.g., Black and Stephens, 1989; Takeuchi et al., 2002). However, past studies have only accounted for adjustment to the hostcountry environment and do not examine adjustment to family life during expatriation. As a result, Lazarova et al. (2010) stressed the need to consider adjustment to the family role to understand the interplay between family members during expatriation. Similar to Black and Gregersen's (1991) definition of adjustment, family role adjustment concerns the feeling of 
comfort, in this case toward the tasks and responsibilities of the family role and toward the interactions with family members (Shaffer et al., 2016). Accordingly, and based on COR theory, we conceive the partner's family role adjustment as a focal contextual resource in the crossover process because it captures the partner's experiences strictly within the family domain.

We propose that through a process of crossover the partner's family role adjustment is transmitted to the expatriate. Positive affective states of other individuals serve as contextual resources (Hobfoll, 2002; ten Brummelhuis and Bakker, 2012) and are thought to cross over directly from one person to the other due to an empathic reaction, similar to mood contagion (Westman, 2001). Specifically, when one partner is well adjusted to the family role, that partner's positive affective state should cross over to the other partner and facilitate his/her own family role adjustment (Lazarova et al, 2010). In other words, a partner's family role adjustment is a contextual resource that should cross over to the expatriate, thereby facilitating the expatriate's resource accumulation and ability to cope with stressors during the expatriate experience. While, to the best of our knowledge, there are no empirical studies on the crossover of family role adjustment, there is strong empirical support for the crossover of adjustment to the host-country environment (Bhaskar-Shrinivas et al., 2005; Takeuchi et al., 2002).

Further, we contend that expatriate self-efficacy acts as another resource that determines when expatriates are particularly affected by their partner's family role adjustment. In line with the equifinality concept in COR theory (i.e., resources may be substituted for one another to reach the same goal, Halbesleben et al., 2014), individuals with high levels of personal resources like self-efficacy can replace (or substitute) contextual resources to still increase their resource endowments and achieve their goals. Key resources like self-efficacy enable individuals to mobilize other resources including energy or mental 
resilience (ten Brummelhuis and Bakker, 2012). Therefore, expatriates with high levels of self-efficacy should have more personal resources at their disposal to meet the various demands posed by novel situations (Cast and Burke, 2002; Chen et al., 2001). As a result, they should be more capable of adjusting to their own family role, irrespective of whether or not their partners are adjusted to their family role.

When expatriates' self-efficacy is low, we expect them to be more affected by the partner's family role adjustment. The resource substitution concept of equifinality suggests that expatriates with low self-efficacy can benefit from their partners' high levels of family role adjustment to adjust to their own family role and meet other family members' needs. However, expatriates with low self-efficacy may also be more susceptible to low levels of partner family role adjustment. According to COR theory, a partner's lack of role adjustment threatens expatriates with resource loss (Halbesleben et al., 2014; Hobfoll, 2001). For example, partners who struggle with adjusting to their new family role can drain expatriates' energy and may require expatriates to spend more time and energy attending to their partners' needs at the expense of other family members. Expatriates with low levels of self-efficacy should also be less able to regulate the risk of negative emotional contagion from their partners (Hatfield et al., 1993).

In sum, we expect that expatriate self-efficacy moderates the crossover between partner family role and expatriate family role adjustment. Specifically, for expatriates with high levels of self-efficacy there should be no crossover. However, without high levels of self-efficacy there will be a positive crossover between partner and expatriate family role adjustment. We propose:

Hypothesis 1: Expatriate general self-efficacy moderates the relationship between partner family role adjustment and expatriate family role adjustment such that there will be a positive relationship when self-efficacy is low, but no relationship when self- 
efficacy is high.

The link between affect and motivation: From expatriate family role adjustment to family role engagement

We expect that the more expatriates are adjusted to their family role the more they are engaged in it. This is in line with COR theory's notion that resources co-travel in caravans such that resources reinforce each other and facilitate the accumulation of other resources (Hobfoll et al., 2018). Specifically, when expatriates experience higher levels of family role adjustment they will feel more comfortable in their role as a family member, which in turn enables them to exert more effort and become engaged in their family role (Lazarova et al., 2010). As Kahn $(1990,1992)$ stated, the conditions for engagement are psychological meaningfulness, psychological safety, and psychological availability, and all three can be facilitated by adjustment. Family role adjustment thus provides expatriates with affective resources that reduce the uncertainties within the family context, enabling expatriates to be more engaged in the family. Empirically, Shaffer et al. (2016) provided some initial evidence for a positive link between expatriate family role adjustment and their family role engagement. Taken together, we propose:

Hypothesis 2: Expatriate family role adjustment is positively related to expatriate family role engagement.

Our previous theorizing implies that, within the boundaries of the family domain, there is an indirect relationship between partner family role adjustment and expatriate family role engagement via expatriate family role adjustment. This represents the process through which affect (i.e., the crossover of adjustment) translates into motivation (i.e., expatriate family role engagement). However, since we expect expatriate self-efficacy to moderate the crossover of adjustment, we propose that the indirect effect is also conditional on the level of 
self-efficacy (i.e., first-stage moderated mediation). Because expatriates with high levels of self-efficacy have more energy and cognitive resources at their disposal to meet situational demands (Cast and Burke, 2002; Chen et al., 2001), they should be more capable of attending to other family members' needs, adjust to them and, in turn, become engaged in their family role irrespective of whether or not their partners are adjusted to their family role.

However, when expatriate self-efficacy is low, expatriates depend on contextual resources — including their partner's family role adjustment — to adjust to their own family role, and in turn become engaged in their family role. Thus, when partners are well adjusted to their family role, expatriates with low self-efficacy may benefit from their partners' positive affective state. At the same time, when partner family role adjustment is low, expatriates with low self-efficacy should be less able to avoid the depletion of their own resources (Hobfoll et al., 2018). In sum, at low levels of expatriate self-efficacy, partner family role adjustment will more likely relate to expatriates' engagement in their family role via their own family role adjustment. Thus:

Hypothesis 3: Expatriate general self-efficacy moderates the indirect relationship between partner family role adjustment and expatriate family role engagement through expatriate family role adjustment such that there will be a positive relationship when self-efficacy is low, but no relationship when self-efficacy is high.

Spillover of motivation: From expatriate family role engagement to expatriate work role engagement

Spillover theory (Crouter, 1984) provides a theoretical rationale for how experiences in one life domain can influence experiences in another domain. It conceptualizes an intrapersonal process in which an individual's attitudes and behaviors transfer from one role to another (Carlson et al., 2006). While the idea of spillover is widely accepted, the exact way 
in which the work and family domains interact has been a subject of debate, and the theoretical and empirical literature has suggested the full gamut of relationships, ranging from negative to non-existent to positive (e.g., Allen and Martin, 2017; Edwards and Rothbard, 2000; Rothbard, 2001).

Although the arguments vary depending on the variables studied, those advancing the idea of a negative interface between the work and family domains tend to focus on a resource-depleting effect of engaging in both work and family roles (Edwards and Rothbard, 2000; Greenhaus and Beutell, 1985; Takeuchi, 2010). Dominating early spillover research, this perspective suggested trade-offs between engaging in the two domains, and that engaging in one role comes at the expense of engaging in another (Byrne and Canato, 2017; Marks, 1977). Such tradeoffs imply the need to choose between domains and that, by extension, choosing to devote more to one domain inevitably leads to devoting less to the other (Edwards and Rothbard, 2000).

By contrast, those proposing a positive interface between the work and family domains (Edwards and Rothbard, 2000; Greenhaus and Powell, 2006) emphasize that simultaneously engaging in work and family may lead to "enrichment" rather than conflict. Engagement in one domain can generate pleasurable experiences and well-being, and it may create additional resources that can be applied to the other role (Edwards and Rothbard, 2000; Greenhaus and Powell, 2006). Indeed, whereas time is finite (this idea is one of the cornerstones of the conflict/depletion argument), engagement is not, and it should not be assumed that engaging in one role automatically means lower engagement in another role (Rothbard, 2001).

In sum, when it comes to engagement in work and family roles, research has advanced two contradictory propositions. On the one hand, individuals with family duties who are very engaged in their family role may deplete their physical, emotional and cognitive 
reserves, thus reducing their engagement at work. On the other, those heavily invested in their family role may generate and transfer positive energy from their family to their work, thereby increasing their engagement at work (Byrne and Canato, 2017). Returning to research on expatriates, Lazarova et al. (2010) specifically considered the relationship between expatriate family role engagement and work role engagement but, given the myriad of possible relationships, their paper included only a general spillover proposition "without specifying whether the relationship will be positive or negative" (p. 106) and explicitly encouraged future research to examine individual variables that may serve as moderators of the relationship. This is consistent with the broader work-life balance literature (e.g., Greenhaus and Powell, 2006; Leslie et al., 2019), which has also called for examining possible moderators of the spillover between the work and family domains.

We expect that the key personal resource of general self-efficacy is a salient moderator because it should facilitate intrapersonal functioning across the family and work domains, both of which compete for resources. In other words, self-efficacy should determine whether family role engagement enables or frustrates work role engagement. Following COR theory (Halbesleben et al., 2014; Hobfoll, 2002), an individual's key personal resources serve to unlock and enable other resources at work and at home. Specifically, expatriates with high levels of self-efficacy should be able to mobilize additional cognitive energy and positive mood (ten Brummelhuis and Bakker, 2012). This should help them experience the family role in positive terms and, in turn, provide them with the necessary resources to engage in their work role. Indeed, new resources may be generated that can be applied to the work role (Greenhaus and Powell, 2006; Ruderman et al., 2002). Individuals are more likely to apply a resource generated in one role domain to another role domain when they believe that applying the resource will have positive consequences (Greenhaus and Powell, 2006). We would expect individuals to more likely perceive benefits of a particular resource for another 
domain (e.g., work) if they are confident that they can succeed in the focal role domain (i.e., family). All this should increase the likelihood that expatriate family role engagement positively spills over to the work domain.

By contrast, at low levels of self-efficacy the expatriates' resources are more likely to be outstretched or exhausted due to being engaged in the family role, thereby leading to depletion. This can lead to frustration and fatigue, which is unlikely to generate new energy that can be deployed to engage in the expatriate's work role. An individual is also less likely to perceive benefits of transferring particular resources, such as interpersonal qualities and the ability to multitask (Ruderman et al., 2002) to another domain (e.g., work) if the individual does not feel confident to succeed in the focal role domain (i.e., family). In sum, we would expect positive spillover between family role and work role engagement at high levels of general self-efficacy, and negative spillover between family role and work role engagement at low levels of general self-efficacy. We propose:

\section{Hypothesis 4: Expatriate general self-efficacy moderates the relationship between} expatriate family role engagement and expatriate work role engagement such that the relationship is positive when self-efficacy is high and negative when it is low.

Our previous arguments imply a second-stage moderated mediation where there is an indirect effect between expatriate family role adjustment and expatriate work role engagement through their family role engagement, conditional on expatriate general selfefficacy. This comprehensively captures the intrapersonal process of spillover between an expatriate's family and work roles. That is, affective family role experiences (i.e., expatriate family role adjustment) translate into a spillover of motivation from their family role to the work role (i.e., spillover of expatriate family to work role engagement). In line with Hypothesis 4, we therefore expect this indirect relationship to be positive when general selfefficacy is high and negative when general self-efficacy is low. Hence: 
Hypothesis 5: Expatriate general self-efficacy moderates the indirect relationship between expatriate family role adjustment and expatriate work role engagement through expatriate family role engagement such that the indirect relationship is positive when self-efficacy is high and negative when it is low.

Taken together, Hypotheses 4 and 5 suggest that whether expatriate family role engagement spills over to positively or negatively affect work role engagement — and whether expatriate family role adjustment positively or negatively relates to expatriate work role engagement via family role engagement — depends on the moderating effect of expatriate self-efficacy. This is an example of a disordinal interaction effect where the sign of the relationship between expatriate family role and work role engagement is contingent on the value of the moderator (see Cohen et al., 2003). Thus, we do not expect a significant relationship between expatriate family role and work role engagement without considering the moderator. As a result, we also do not expect a simple serial indirect effect from partner family role adjustment to expatriate work role engagement without accounting for the moderating role of self-efficacy.

\section{Methods}

Sample and procedure

Our study was part of a larger data collection conducted to assess the work and family experiences of global employees and their partners. Data for the present study came from seven organizations across two time points. Four of these were multinational companies, one was an expatriate association, one was a university alumni association, and one was a foreign affairs ministry. We contacted executives in each organization and requested our first online survey to be forwarded to the global employees who were currently employed with the company/embassy, were members of an expatriate organization, or were university alumni. 
At the beginning of the survey, participants received definitions for the terms 'corporate and self-initiated expatriates' and selected the one that corresponded to their current situation. The participants from the foreign affairs ministry were all diplomats at a foreign posting.

A total of 1,477 expatriates participated in our study at Time 1 . Since the organizations themselves distributed the survey, we could not track how many invitations were sent out, thus making it impossible to calculate a response rate. To test our model, we needed multi-source data from expatriates and their partners. Thus, the expatriates who were married or in a committed relationship were asked to provide their partners' contact information. We then contacted the partners and asked them to complete a separate online survey. We informed expatriates and partners that survey participation and provision of contact details for their significant other is voluntary and that their data would be kept confidential. Respondents were entered in a lucky draw to win a US\$100 gift card. Out of the 1,477 expatriates, we obtained contact information for a total of 564 partners, who were each sent a partner survey at Time 1 . Of these, we received 206 completed surveys (a response rate of $37 \%$ ) with the information necessary to match the expatriate and partner data. To mitigate the threat of common method bias (Podsakoff et al., 2003) and assess the temporal ordering of the crossover and spillover processes, we not only collected data from multiple sources but also asked expatriates to complete a second follow-up survey approximately three months after completion of the data collection at Time 1. In short, while we used the expatriate and partner surveys at Time 1 to measure partner family role adjustment, expatriate family role adjustment, and expatriate general self-efficacy, expatriate responses at Time 2 were used to measure expatriate family role engagement and work role engagement.

Of the 206 expatriates at Time 1, we received 105 completed Time 2 surveys for a retention rate of $51 \%$. As a result, the final sample is comprised of 105 couples, which we used to test all our hypotheses. We checked for non-response bias across waves, by 
comparing expatriates with matching partner data who responded only at Time $1(n=101)$ with those who responded to both surveys across several demographic variables. The respondents who completed both waves did not differ significantly from those who only participated in the first wave. Thus, the sample at Time 2 is likely representative of the larger sample at Time 1.

Expatriates were mostly male (79\%), had been in the host country for a little over two years on average, and 58\% had at least one child accompanying them abroad. Their mean age was 44 years and they had been married or in a committed relationship for an average of 16 years. The sample consisted of 40 diplomats, 58 corporate, and seven self-initiated expatriates. The expatriate partners were on average 44 years old. Approximately $90 \%$ of the partners had relocated with the expatriate and $64 \%$ were currently unemployed. The majority of expatriates were French (57\%) and the rest of the sample was diverse (e.g., Spain, Sweden, USA, India). No one host country was dominant and host countries were representative of six continents.

\section{Measures}

Given our diverse sample, we made the survey available in several languages (i.e., English, Spanish, and French). The surveys were translated into Spanish and French from the English version and then back-translated to ensure accuracy.

Partner family role adjustment and expatriate family role adjustment were assessed with a measure from Shaffer et al. (2016). This measure consisted of six items $(1=$ not at all to $5=$ to a great extent). Respondents were asked to rate the extent to which they feel comfortable with aspects of their family life since they, or their partner, became a global employee. A sample item is: "My participation in family activities and tasks" and the internal consistency reliabilities for partner and expatriate family role adjustment were .83 and .88 , respectively. 
We measured expatriate general self-efficacy with a scale from Chen et al. (2001). The measure consisted of eight items $(1=$ strongly disagree to $5=$ strongly agree $)$. A sample item is: "I will be able to successfully overcome many challenges" and this measure's reliability was .91 .

Expatriates' family role engagement was measured using a slightly modified scale from Rothbard (2001). This measure consists of nine items $(1=$ strongly disagree to $7=$ strongly agree) and captures both the attention (four items) and absorption (five items) aspects of engagement. Sample items are: "I focus a great deal of attention on my family" (attention) and "When I am with my family, I often lose track of time" (absorption).

Work role engagement was measured with Rothbard's (2001) scale and consists of nine items, again capturing the attention and absorption aspects of engagement. The items were measured from $1=$ strongly disagree to $7=$ strongly agree. Sample items are: "I focus a great deal of attention on my work" (attention) and "When I am working, I am completely engrossed by my work" (absorption).

We conducted a confirmatory factor analysis (CFA) to evaluate the structure of the family and work role engagement constructs, which were each conceptualized as consisting of two distinct dimensions: attention and absorption (Rothbard, 2001). We compared a series of measurement models in Mplus 8.2 with robust maximum likelihood estimation starting with a model that combined the absorption and attention dimensions. This two-factor model did not demonstrate an acceptable fit $\left(N=105 ; \chi^{2}=728.75, p<.001 ; d f=134 ; \mathrm{CFI}=.56\right.$; RMSEA $=.21 ; \mathrm{SRMR}=.15)$. The four-factor model on the other hand showed a considerable improvement $\left(N=105 ; \chi^{2}=327.30, p<.001 ; d f=129 ; \mathrm{CFI}=.85 ; \mathrm{RMSEA}=\right.$ .12 ; SRMR $=.10)$. However, the model still did not fit the data well and there were two items cross-loading on other factors (i.e., "I pay a lot of attention to my family" and "Nothing can distract me when I am taking care of my family"). Removing these cross-loading items 
avoids introducing bias in the analysis as a result of possible partial overlap between the dimensions (Kline, 2011). Upon removal of these two items, the four-factor model fit the data well $\left(N=105 ; \chi^{2}=157.01, p<.001 ; d f=98 ; \mathrm{CFI}=.95 ; \mathrm{RMSEA}=.08 ; \mathrm{SRMR}=.05\right)$ and all loadings were significant and above 0.60 . Thus, we test our hypotheses by looking specifically at the attention and absorption dimensions of family and work engagement. The reliabilities for work role engagement were .90 (attention) and .92 (absorption) and for family role engagement they were .91 (attention) and .93 (absorption).

We considered controlling for several demographic variables. These were gender $(0=$ male, 1 = female), age (in years), current expatriate assignment duration (in years), number of family members accompanying the expatriate $(0=$ no relocated family members to $5=$ partner and four children $)$, partner current employment $(0=$ not employed, $1=$ employed $)$ and expatriate type $(0=$ diplomats, $1=$ corporate and self-initiated expatriates $)$. In addition, we accounted for expatriate cultural adjustment at Time 1 as a control variable. Cultural adjustment, which represents expatriates' adjustment to the general conditions in the hostcountry (Black and Stephens, 1989) is considered to have an association with family role adjustment (Lazarova et al., 2010) and evidence suggests that it also influences the work context (Bhaskar-Shrinivas et al., 2005). Cultural adjustment was measured with an eightitem scale $(1=$ not at all to $5=$ to a great extent $)$ adapted from Black and Stephens' (1989) measure. The reliability was .87. Finally, we controlled for prior levels of expatriate family and work role engagement by relating them to their respective Time 2 counterparts. Equivalent to the measures at Time 2, the four-factor model for work and family role engagement at Time 1 also had an acceptable fit to the data $\left(N=105 ; \chi^{2}=176.80, p<.001\right.$; $d f=98 ; \mathrm{CFI}=.92 ; \mathrm{RMSEA}=.09 ; \mathrm{SRMR}=.06)$ and was better than a two-factor model $(N=$ $\left.105 ; \chi^{2}=394.70, p<.001 ; d f=103 ; \mathrm{CFI}=.70 ; \mathrm{RMSEA}=.16 ; \mathrm{SRMR}=.11\right)$. For family role engagement at Time 1 reliabilities were .83 (attention) and .93 (absorption), and for work role 
engagement these were .88 (attention) and .85 (absorption).

\section{Analytical procedures}

Table 1 presents means, standard deviations, correlations, and reliabilities of the study variables. We first examined the correlations between our suggested controls and focal variables. All controls, with the exception of assignment duration and accompanying family members, were significantly correlated with one or more of the focal dependent variables. Consequently, we present our results without these two control variables (Bernerth and Aguinis, 2016). Note that the results remain unchanged when the two controls are included.

\section{INSERT TABLE 1 ABOUT HERE}

Given our relatively small sample $(\mathrm{n}=105)$ and the need to test complex moderated mediation models with many variables, we used a series of ordinary least squares regressions (see Tables 2 and 3) in SAS 9.4 to test our hypotheses. To test for moderated mediation (Hypotheses 3 and 5) in an integrative manner, we used the PROCESS macro v.3.2.01 for SAS (Hayes, 2018), which is also based on ordinary least squares regression. The macro uses bootstrapping $(k=10,000)$ to assess the significance of conditional indirect effects (i.e., moderated mediation) and generates percentile bootstrap confidence intervals. To accurately assess the indirect effects, the process macro also includes the direct relationship from the independent variables to the outcomes. All continuous independent variables were mean centered to aid in interpreting the interaction effects (Aiken and West, 1991).

\section{Results}

To test Hypothesis 1, we first examined whether there is a significant effect for the crossover between partner and expatriate family role adjustment beyond our control variables, which is indeed the case $\left(b=.38, S E=.10, p=.000, \Delta R^{2}=.10\right)$. Hypothesis 1 
suggests that this crossover effect between partner and expatriate family role adjustment will be moderated by expatriate general self-efficacy. The interaction effect was significant $(b=-$ $\left..33, S E=.15, p=.033, \Delta R^{2}=.03\right)$. The crossover was positive when self-efficacy was low ($1 S D)(b=.54, S E=.14, p=.001)$ and was not significant when self-efficacy was high $(+1$ $S D)(b=.15, S E=.13, p=.225)$ (see Figure 2), which supports Hypothesis 1. Further, expatriate family role adjustment significantly related to the attention dimension of family role engagement $\left(b=.36, S E=.14, p=.015, \Delta R^{2}=.04\right)$ but failed to reach significance at the $p<.05$ level in relation to the absorption dimension $\left(b=.26, S E=.13, p=.051, \Delta R^{2}=.02\right)$. This partially supports Hypothesis 2 .

\section{INSERT TABLES 2 AND 3 ABOUT HERE}

In Hypothesis 3, we proposed a first-stage moderated mediation in which the indirect effect between partner family role adjustment and expatriate family role engagement through expatriate family role adjustment would be conditional on the level of expatriate general selfefficacy. A significant conditional indirect effect is inferred when the confidence interval for the index of moderated mediation does not contain zero (Hayes, 2015). We indeed found that the nature of this indirect relationship differs depending on the level of general self-efficacy in relation to the attention dimension of expatriate family role engagement (index of moderated mediation $=-.11$, Boot $S E=.06,95 \%$ Boot $\mathrm{CI}=-.2393,-.0013)$. Specifically, the indirect relationship between partner family role adjustment and expatriate family role engagement (attention) was significantly positive when self-efficacy was low $(-1 S D)$ (indirect effect $=.18$, Boot $S E=.08,95 \%$ Boot CI $=.0298, .3339$ ), but not when self-efficacy was high (indirect effect $=.05$, Boot $S E=.05,95 \%$ Boot $\mathrm{CI}=-.0281, .1813$ ). By contrast, the moderated mediation in relation to the absorption dimension of family role engagement was not significant (index of moderated mediation $=-.09$, Boot $S E=.07,95 \%$ Boot $\mathrm{CI}=-$ 
$.2396, .0102)$. In addition, the direct effect of partner family role adjustment in the presence of the mediator was not significant in relation to both family role engagement attention $(b=$ $.09, S E=.16, p=.574)$ and absorption $(b=-.01, S E=.15, p=.937)$. In sum, these results support Hypothesis 3 for the attention dimension of family role engagement.

As we expected, family role engagement did not have a significant direct relationship with work role engagement. Specifically, family role attention and absorption neither significantly related to the attention dimension of work role engagement $(b=.05, S E=.06, p$ $=.424$ for family role attention, $b=-.09, S E=.06, p=.123$ for family role absorption) nor to the absorption dimension $(b=-.02, S E=.08, p=.815$ for family role attention, $b=.09, S E=$ $.08, p=.285$ for family role absorption). Hypothesis 4 states that expatriate general selfefficacy will moderate the relationship between expatriate family role engagement and work role engagement. The moderating effect was only significant with regard to the relationship between the attention dimensions of family role and work role engagement $(b=.24, S E=.09$, $p=.008, \Delta R^{2}=.03$ ) and between the absorption dimension of family role engagement and the attention dimension of work role engagement $\left(b=.22, S E=.07, p=.002, \Delta R^{2}=.05\right)$. When self-efficacy was high $(+1 S D)$, the family role engagement (attention) - work role engagement (attention) relationship was positive and significant $(b=.18, S E=.08, p=.018)$ and was not significant when self-efficacy was low $(-1 S D)(b=-.10, S E=.08, p=.231)$ (see Figure 3). On the other hand, for the family role engagement (absorption) - work role engagement (attention) relationship, when self-efficacy was high $(+1 S D)$ the relationship was not significant $(b=.02, S E=.07, p=.793)$, but it was negative and significant when self-efficacy was low $(-1 S D)(b=-.23, S E=.07, p=.002)$ (see Figure 3). Thus, Hypothesis 4 is partially supported.

INSERT FIGURES 2 AND 3 ABOUT HERE 
Hypothesis 5 proposed that the indirect effect between expatriate family role adjustment and expatriate work role engagement, mediated by their family role engagement, would be conditional on expatriate general self-efficacy. We found support for moderated mediation for the indirect effect between expatriate family role adjustment and work role engagement (attention) through family role engagement (attention) (index of moderated mediation $=.09$, Boot $S E=.05,95 \%$ Boot $\mathrm{CI}=.0175, .2005)$. Specifically, this indirect effect was only positive and significant when self-efficacy was high (+1 SD) (indirect effect $=.07$, Boot $S E=.03,95 \%$ Boot $\mathrm{CI}=.0139, .1471)$ and not when it was low $(-1 \mathrm{SD})$ (indirect effect $=-.03$, Boot $S E=.03,95 \%$ Boot $\mathrm{CI}=-.1165, .0105)$. In addition, the direct effect from expatriate family role adjustment to work role engagement (attention) was not significant in the presence of the mediator $(b=-.04, S E=.09, p=.679)$. The index of moderated mediation for the conditional indirect effect to work role engagement (attention) through family role engagement (absorption) was not significant. There was also no evidence for moderated mediation when the absorption dimension of work role engagement was the outcome of interest. Overall, this provides partial support for Hypothesis 5. For the sake of completeness, we also tested the potential serial moderated mediation for the entire modeli.e., from partner family role adjustment to expatriate work role engagement (see Figure 1) and report the results in the Appendix.

\section{Discussion}

Integrating COR with crossover and spillover theories, we conceptualize and empirically show when partner family role adjustment influences expatriates' family role adjustment and engagement, and how and when these experiences translate into expatriate work role engagement. Specifically, our results suggest that expatriate general self-efficacy is a salient boundary condition for both crossover and spillover at the work-family interface during expatriation. We find that expatriates with high levels of self-efficacy experience no 
crossover between partner family role adjustment and expatriate family role adjustment, while benefiting from positive spillover between their family role engagement (attention dimension) and their work role engagement (attention dimension). By contrast, expatriates with low self-efficacy experience strong positive crossover between partner family role adjustment and expatriate family role adjustment, while also suffering from negative spillover between their family role engagement (absorption dimension) and their work role engagement (attention dimension).

\section{Theoretical implications}

Our study makes several contributions to COR theory, the literatures on crossover and spillover processes, and the work-family interface during expatriation. First, by conceiving partner family role adjustment as a contextual resource for the expatriate, we advance COR theory. Except for the newcomer literature (e.g., Saks and Ashforth, 2000), the affective construct of adjustment has received little attention outside the expatriation context. Importantly, while the partner's family role adjustment may be a typically stable contextual resource, much like marriage more generally (Hobfoll, 2002; ten Brummelhuis and Bakker, 2012), it becomes more volatile when the family undergoes major role transitions, as in the case of cross-border relocations. The construct of family role adjustment is reflective of the volatility in the family domain due to a major role transition. However, we contend that adjustment is not only relevant to the expatriation context but captures a unique state during a range of other prominent role transitions, including career moves, changes induced by external shocks like COVID-19 and other relevant life role transitions. It therefore promises to advance our understanding of COR theory explanations of personal and professional change more broadly.

In a related vein, drawing on the idea that resources co-travel in resource caravans (Hobfoll et al., 2018), the expatriation context allows us to study how personal and contextual 
resources interact and, in fact, may compensate for one another in the resource accumulation process. Specifically, we theorized and empirically demonstrated that the key personal resource of expatriate self-efficacy can compensate for more transient contextual resources, such as partner family role adjustment. This is important because the individual has more control over personal resources compared to contextual resources, especially during periods of role transitions. However, available contextual resources may also compensate for scarce personal resources. In other words, expatriates with low levels of self-efficacy can benefit from their partners' adjustment to the family role. Indeed, our results suggest that the level of expatriate family role adjustment is very similar (1) at low levels of self-efficacy and high levels of partner family role adjustment and (2) at high levels of self-efficacy and low levels of partner family role adjustment, respectively. While scholars have pointed to the equifinality concept to suggest that individuals can substitute resources to achieve the same goal (e.g., Halbesleben et al., 2014), our findings suggest that such substitution is not limited to versatile and stable resources like personality factors but it also pertains to certain contextual and more volatile resources.

Second, scholars have repeatedly called for examining salient moderators, especially the role of key personal resources (Hobfoll et al., 2018; ten Brummelhuis and Bakker, 2012), to advance our understanding of the conditions whereby crossover and spillover may more or less likely occur. Although self-efficacy is a prominent concept in social psychology (e.g., Bandura, 1997; Cast and Burke, 2002; Chen et al., 2001; Gist and Mitchell, 1992) and serves as a key resource in COR theory in particular (Hobfoll et al., 2018), it has received little attention as a moderator of crossover and spillover. Our contention that general self-efficacy can compensate for low levels of contextual resources from the family unit to help expatriates adapt psychologically to their family role reinforces a consistent theme in the management literature, namely, the adaptive benefits of general self-efficacy (Schaubroeck et al., 2000; 
Siu et al., 2007). Further, by focusing on general self-efficacy as a cognitive resource, our study also moves beyond the focus on affective and behavioral mechanisms for how the work and family domains influence each other (Leslie et al., 2019).

Our finding that the crossover between partner and expatriate family role adjustment was not significant at high levels of expatriate general self-efficacy has additional implications for COR and crossover theory, and expatriate research more broadly. Specifically, whereas personal resources such as general self-efficacy allow individuals to sustain work motivation and expend further energy towards an activity or regulate the level of stress they experience, personal resources may also desensitize individuals to other relevant stakeholders. To the extent that family members' affective states are potential sources of strain for the focal individual, personal resources such as general self-efficacy can serve as buffers (Cast and Burke, 2002; Brockner, 1988). This is consistent with the predominant focus on a stressor-stress-strain model in expatriate research (Black et al., 1991) and the study of negative antecedents to work-related outcomes such as partner maladjustment (see Bhaskar-Shrinivas et al., 2005). However, to the extent that personal resources desensitize individuals to their partners' feelings and psychological states, it is also possible that the health of the relationship between the couple suffers. Thus, high levels of self-efficacy may function as a double-edge sword in the relationship. While our study did not focus on this potential consequence, we encourage future research to examine this more closely and extend COR theory to consider not only the positive but also the potential negative effects for relevant stakeholders. Similarly, while we zeroed in on the partner's family role adjustment and conceived it as a contextual resource for the expatriate, future studies should also account for the partner's role more broadly. For example, studies can examine partners' other family role experiences, such as their own engagement, but also the couples' joint family experiences like marital satisfaction. For dual-career couples, it would 
also be beneficial to examine the expatriate's influence on the partner's own work experiences.

In a related vein, by conceiving general self-efficacy as a boundary condition to crossover, we also contribute to expatriate research that has assumed strong crossover in adjustment between the partner and the expatriate to be automatic (Takeuchi et al., 2002; Takeuchi, 2010). Our results suggest that this is not the case under conditions of high selfefficacy. We would speculate that the strength of crossover in adjustment may also depend on other key personal resources that have not been studied much in the expatriate literature thus far—such as emotional intelligence and optimism—or the family unit—such as joint experience with international relocations. Future research may further examine these and other boundary conditions to advance our understanding of crossover and spillover processes during international assignments, and ultimately expatriate effectiveness.

Third, we establish that expatriate family role engagement is an important influence on their work engagement. While previous research has begun to uncover the within-person processes through which work and family life are interlinked (e.g., Ilies et al., 2017), we know little about how engagement in the family unit may affect salient work-related outcomes. Our results contribute to spillover theory and the broader work-family interface literature by integrating two contradictory propositions as to whether individuals' engagement in family and domestic duties may enrich or deplete their physical, emotional and cognitive reserves, thus either positively or negatively affecting engagement at work (Byrne and Canato, 2017; Leslie et al., 2019). This expands our understanding of the workfamily interface because depletion and enrichment arguments tend to be examined separately (Rodríguez-Muñoz et al., 2014; Takeuchi, 2010) or, if considered jointly (Rothbard, 2001), they are not examined along with the antecedents or consequences of engagement in the family and work domains. 
Interestingly, we found that the moderating role of general self-efficacy differed regarding the two dimensions of engagement and was more prevalent for the attention dimension compared to the absorption dimension. Whereas attention captures the duration of focus on and mental preoccupation with a given role, absorption concerns the intensity of focus on the work and family roles. As Rothbard (2001) argues, attention can be conceived as a resource-based motivational construct, while absorption reflects a more intrinsic motivational construct. In other words, attention serves as an invisible, cognitive resource that individuals may deploy in different ways. Thus, attention to the family role may signal to the focal individual sufficient cognitive capacity that can be extended to the work role, thereby increasing attention to the work role. Attention is therefore more likely to be influenced by general self-efficacy, which is equally conceived as a cognitive, personal resource (Bandura, 1986). Overall, our results suggest that COR theory arguments may be more adept at explaining the boundary conditions of spillover processes for the attention than for the absorption dimension of engagement.

In contrast to attention, absorption appears to tap into more affective and interestbased facets of engagement (Rothbard, 2001). In our study, we found that spillover between the absorption dimension of family role engagement and the attention dimension of work role engagement was significantly negative at low levels of expatriate general self-efficacy but not significant at high levels of general self-efficacy. This suggests that being absorbed in the family role may deplete an individual's resources that could otherwise be used for attention to the work role such that it increases positive emotions regarding activities in the family domain. These positive emotions may indicate less availability for work role-related activities, unless the individual can draw on additional personal resources, such as high levels of general self-efficacy.

Finally, we move beyond the predominant focus on expatriate and partner adjustment 
(Shaffer and Harrison, 2001; Takeuchi, 2010) to consider how and when expatriates' experiences in the family domain are related to work outcomes. Further, by demonstrating both negative and positive ways in which experiences in the family domain affect the focal expatriate, we integrate the predominant stressor-stress-strain paradigm in expatriate research (e.g., Black et al., 1991) with a more recent focus on the beneficial aspects of global work (e.g., Nurmi and Hinds, 2016).

\section{Practical implications}

Our findings have several implications for corporate practice. Given the important role of family role engagement for work role engagement, organizations are well advised to help support and cultivate their expatriates' family role engagement. Our findings point to at least two ways that organizations can improve expatriates' family role engagement: organizational support as well as selection and training. First, organizations should give their employees the opportunity to participate more actively in their family roles. For example, organizations may provide more time off, especially at the beginning of the relocation, and avoid overburdening expatriates due to back-to-back travel demands. They may also offer flexible work practices and flexible office hours to expatriates. Organizations should also provide more support to family members in order to facilitate their international experience. To the extent that partners experience the international relocation as less taxing, they will be more adjusted to their family role, which may help the expatriate to be more adjusted and, ultimately, engaged in their family role.

Second, global mobility professionals should focus on hiring expatriates with high levels of general self-efficacy or providing extra support for those with low levels of selfefficacy. This is particularly important if social norms in the host context differ greatly from the home environment, there is a lack of employment opportunities, or the partner will experience substantial changes in family dynamics due to a sudden increase in the 
expatriate's work or travel requirements. Organizations may also provide workshops to increase self-efficacy or teach managers how to develop it. At the same time, such organizational interventions may not necessarily work for those who already have high levels of self-efficacy because they may be less susceptible to external stimuli. If it can be further shown that interventions aiming to increase self-efficacy—or support expatriates more broadly-help trainees with low levels but not those with high levels of self-efficacy, training costs could be saved by only training the former individuals. Training effectiveness may be further improved by identifying what works for those with high levels of self-efficacy. For example, coaching might help with developing tactics to leverage positive experiences in the family domain.

\section{Limitations and future research}

Although we proposed and tested a theory-based model and collected data at multiple time points and from multiple sources, our study is not without limitations, which represent avenues for future research. First, our research design precludes us from making causal claims. Despite data from two time points, we are unable to eliminate all possible confounding effects due to omitted variables, or to firmly establish temporal ordering. While causation is best determined through experiments, such a design was not feasible from a practical standpoint, given the type of variables and intra- and inter-individual mechanisms we examined. Nevertheless, the causal ordering of the variables in our model has been informed by theory.

Second, the number of matched expatriate-partner dyads is limited. Although our sample size is somewhat lower than previous expatriate research that studied matched couples (e.g., Shaffer and Harrison, 1998; Takeuchi et al. 2002), we collected data at two distinct time points to expand on prior work. This likely explains the increased sample attrition. A larger sample would have allowed us to test our conceptual model in a more 
integrative manner. For example, while we took a directional approach to examine the predictors and moderating conditions affecting expatriate work role engagement, we would welcome research that also captures the bidirectionality inherent in crossover and spillover processes. Similarly, this could involve conceptualizing and measuring not only the role of expatriates' general self-efficacy but also their partners' self-efficacy. However, teasing out the predictors, consequences and boundary conditions of crossover and spillover while accounting for their reciprocal nature would entail more sophisticated research designs and data requirements, which are particularly difficult to come by in the expatriate domain (Tharenou, 2015). Further, although our findings did not show any significant effect of expatriates' accompanying children, scholars have called for more research on understanding how children can influence expatriates' effectiveness (Dimitrova, 2018) and we would encourage future studies to examine this in greater detail.

Third, while work engagement has been established as a key predictor of work performance (e.g., Christian et al., 2011), we would encourage future studies to explicitly test the work performance implications of our conceptual model. We also acknowledge that expatriate effectiveness is necessarily a multidimensional construct that reaches beyond the individual expatriate and the immediate assignment context (Reiche and Harzing, 2018) and we would invite future studies to expand our findings to other measures of effectiveness.

\section{Conclusion}

As de Lamartine pointed out in the opening quote, individuals are inherently intertwined with others, especially with their family members. In fact, the COVID-19 crisis has greatly increased the need for remote work, which has further weakened the boundaries within the family unit and between work and non-work domains, thereby making crossover and spillover even more prevalent. It is surprising that little research to date has examined exactly how and under which conditions experiences in the family domain are related to 
various dimensions of expatriate effectiveness. Our findings may better equip scholars and managers to realize the potential that the positive dynamics between the family and work spheres hold for both individuals and organizations.

\section{Acknowledgements}

We would like to express our gratitude to Gilad Chen, Yu-Ping Chen, David Harrison, YuShan Hsu and Sebastian Stoermer for their valuable advice and constructive comments on earlier versions of this manuscript.

\section{Funding}

Ministry of Science and Innovation of Spain MICINN-ECO2012-33544, U.S. - Israel Binational Science Foundation 2009106. Mila Lazarova acknowledges support of the Canada Research Chair Program. 


\section{References}

Aiken LS and West SG (1991) Multiple Regression: Testing and Interpreting Interactions. Thousand Oaks, CA: Sage.

Cohen J, Cohen P, West SG and Aiken LS (2003) Applied Multiple Regression/Correlation Analysis for the Behavioral Sciences (3rd ed.). Mahwah, NJ: Erlbaum Associates.

Allen TD and Martin A (2017) The work-family interface: A retrospective look at 20 years of research in JOHP. Journal of Occupational Health Psychology 22: 259-272.

Bacharach SB, Bamberger P and Biron M (2010) Alcohol consumption and workplace absenteeism: The moderating effect of social support. Journal of Applied Psychology 95: $334-348$.

Bakker AB, Demerouti E and Dollard MF (2008) How job demands affect partners' experience of exhaustion: Integrating work-family conflict and crossover theory. Journal of Applied Psychology 93: 901-911.

Bandura A (1997) Self-efficacy: The Exercise of Control. New York: Freeman.

Bandura A (1986) Social Foundations of Thought and Action: A Social Cognitive Theory. Englewood Cliffs, NJ: Prentice-Hall.

Bernerth JB and Aguinis H (2016) A critical review and best-practice recommendations for control variable usage. Personnel Psychology 69: 229-283.

Bhaskar-Shrinivas P, Harrison DA, Shaffer MA and Luk DM (2005) Input-based and timebased models of international adjustment: Meta-analytic evidence and theoretical extensions. Academy of Management Journal 48: 257-281.

Black JS and Gregersen HB (1991) Antecedents to cross cultural adjustment for expatriates in Pacific Rim assignments. Human Relations 44: 497-515. 
Black JS and Stephens GK (1989) The influence of the spouse on American expatriate adjustment and intent to stay in Pacific Rim overseas assignments. Journal of Management 15: 529-544.

Black JS, Mendenhall M and Oddou G (1991) Toward a comprehensive model of international adjustment: An integration of multiple theoretical perspectives. Academy of Management Review 16: 291-317.

Bolger N, DeLongis A, Kessler RC and Wethington E (1989) The contagion of stress across multiple roles. Journal of Marriage and the Family 51: 175-183.

Brockner J (1988) Self-esteem at Work: Research, Theory, and Practice. Lexington, MA: Lexington Books.

Byrne JM and Canato A (2017) It's been a hard day's night: Work family interface and employee engagement. Organizational Dynamics 46: 104-112.

Caligiuri PM, Hyland MAM, Joshi A and Bross AS (1998) Testing a theoretical model for examining the relationship between family adjustment and expatriates' work adjustment. Journal of Applied Psychology 83: 598-614.

Carlson DS, Kacmar KM, Wayne JH and Grzywacz JG (2006) Measuring the positive side of the work-family interface: Development and validation of a work-family enrichment scale. Journal of Vocational Behavior 68: 131-164.

Carlson DS, Thompson MJ, Crawford WJ and Kacmar KM (2019) Spillover and crossover of work resources: A test of the positive flow of resources through work-family enrichment. Journal of Organizational Behavior 40: 709-722.

Cast AD and Burke PJ (2002) A theory of self-esteem. Social Forces 80: 1041-1068.

Chen G, Gully SM and Eden D (2001) Validation of a new general self-efficacy scale. Organizational Research Methods 4: 62-83. 
Chen G, Kirkman BL, Kim K, Farh CI and Tangirala S (2010) When does cross-cultural motivation enhance expatriate effectiveness? A multilevel investigation of the moderating roles of subsidiary support and cultural distance. Academy of Management Journal 53: 1110-1130.

Christian MS, Garza AS and Slaughter JE (2011) Work engagement: A quantitative review and test of its relations with task and contextual performance. Personnel Psychology 64: 89-136.

Crouter AC (1984) Spillover from family to work: The neglected side of the work-family interface. Human Relations 37: 425-441.

Dimitrova M (2018) Expatriation and the work-family interface. In KM Shockley, W Shen and RC Johnson (Eds) The Cambridge Handbook of the Global Work-Family Interface: pp. 479-494. Cambridge: Cambridge University Press.

Edwards JR and Rothbard NP (2000) Mechanisms linking work and family: clarifying the relationship between work and family constructs. Academy of Management Review 25: 178-199.

Eisenhardt KM (1989) Building theories from case study research. Academy Management Review 14: 532-550.

Ferguson M, Carlson D and Kacmar KM (2015) Flexing work boundaries: The spillover and crossover of workplace support. Personnel Psychology 68: 581-614.

Gist ME and Mitchell TR (1992) Self-efficacy: A theoretical analysis of its determinants and malleability. Academy of Management Review 17: 183-211.

Greenhaus JH and Beutell NJ (1985) Sources of conflict between work and family roles. Academy of Management Review 10: 76-88.

Greenhaus JH and Powell GN (2006) When work and family are allies: A theory of workfamily enrichment. Academy of Management Review 31: 72-92. 
Halbesleben JRB, Neveu J-P, Paustian-Underdahl SC and Westman M (2014) Getting to the "COR": Understanding the role of resources in conservation of resources theory. Journal of Management 40: 1334-1364.

Haslberger A, Brewster C and Hippler T (2013) The dimensions of expatriate adjustment. Human Resource Management 52: 333-351.

Hatfield E, Cacioppo JT and Rapson RL (1993) Emotional contagion. Current Directions in Psychological Science 2: 96-100.

Hayes AF (2015) An index and test of linear moderated mediation. Multivariate Behavioral Research, 50: 1-22.

Hayes AF (2018) Introduction to Mediation, Moderation, and Conditional Process Analysis: A Regression-based Approach (2 ${ }^{\text {nd }}$ ed.). New York, NY: The Guilford Press.

Hobfoll SE (2001) The influence of culture community and the nested-self in the stress process: Advancing conservation of resources theory. Applied Psychology: An International Review 50: 337-421.

Hobfoll SE (2002) Social and psychological resources and adaptation. Review of General Psychology 6: 307-324.

Hobfoll SE, Halbesleben J, Neveu J-P and Westman M (2018) Conservation of resources in the organizational context: The reality of resources and their consequences. Annual Review of Organizational Psychology and Organizational Behavior 5: 103-128.

Ilies R, Liu XY, Liu Y and Zheng X (2017) Why do employees have better family lives when they are highly engaged at work? Journal of Applied Psychology 102: 956-970.

Kahn WA (1990) Psychological conditions of personal engagement and disengagement at work. Academy of Management Journal 33: 692-724.

Kahn WA (1992) To be fully there: Psychological presence at work. Human Relations 45: $321-349$ 
Kline RB (2011) Principles and Practice of Structural Equation Modeling (3rd ed.). New York, NY: The Guilford Press.

Lazarova M, Westman M and Shaffer MA (2010) Elucidating the positive side of the workfamily interface on international assignments: A model of expatriate work and family performance. Academy of Management Review 35: 93-117.

Leslie LM, King EB and Clair JA (2019) Work-life ideologies: The contextual basis and consequences of beliefs about work and life. Academy of Management Review 44: 7298.

Liu J, Kwan HK, Lee C and Hui C (2013) Work-to-family spillover effects of workplace ostracism: The role of work-home segmentation preferences. Human Resource Management 52: 75-93.

Malek MA, Budhwar P and Reiche BS (2015) Sources of support and expatriation: A multiple stakeholder perspective of expatriate adjustment and performance in Malaysia. International Journal of Human Resource Management 26: 258-276.

Marks SR (1977) Multiple roles and role strain: Some notes on human energy, time and commitment. American Sociological Review 42: 921-936.

Neff A, Niessen C and Sonnentag S (2013) Expanding crossover research: The crossover of job-related self-efficacy within couples. Human Relations 66: 803-827.

Niessen C, Weseler D and Kostova P (2016) When and why do individuals craft their jobs? The role of individual motivation and work characteristics for job crafting. Human Relations 69: 1287-1313.

Nurmi N and Hinds P (2016) Job complexity and learning opportunities: A silver lining in the design of global virtual work. Journal of International Business Studies 46: 631-654.

Parker SK, Bindl UK and Strauss K (2010) Making things happen: A model of proactive motivation. Journal of Management 36: 827-856. 
Phillips JM and Gully SM (1997) Role of goal orientation, ability, need for achievement, and locus of control in the self-efficacy and goal-setting process. Journal of Applied Psychology 82: 792-802.

Podsakoff PM, MacKenzie SB, Lee JY and Podsakoff NP (2003) Common method biases in behavioral research: A critical review of the literature and recommended remedies. Journal of Applied Psychology 88: 879-903.

Powell GN, Greenhaus JH, Allen TD and Johnson RE (2019) Introduction to Special Topic Forum: Advancing and expanding work-life theory from multiple perspectives. Academy of Management Review 44: 54-71.

Reiche BS and Harzing A-W (2018) International assignments. In BS Reiche, A-W Harzing and H Tenzer (Eds) International Human Resource Management ( $5^{\text {th }}$ ed.): $159-207$. London: Sage.

Rodríguez-Muñoz A, Sanz-Vergel AI, Demerouti E and Bakker AB (2014) Engaged at work and happy at home: A spillover-crossover model. Journal of Happiness Studies 15: 271-283.

Rofcanin Y, Las Heras M, Bosch MJ, Wood G and Mughal F (2019) A closer look at the positive crossover between supervisors and subordinates: The role of home and work engagement. Human Relations 72: 1776-1804.

Rothbard NP (2001) Enriching or depleting? The dynamics of engagement in work and family roles. Administrative Science Quarterly 46: 655-684.

Ruderman MN, Ohlott PJ, Panzer K and King SN (2002) Benefits of multiple roles for managerial women. Academy of Management Journal 45: 369-386.

Saks AM and Ashforth BE (2000) The role of dispositions, entry stressors, and behavioral plasticity theory in predicting newcomers' adjustment to work. Journal of Organizational Behavior 21: 43-62. 
Santa Fe Relocation (2021) Global Mobility Survey 2020/21: Challenging Change. Santa Fe Relocation.

Schaubroeck J, Lam SS and Xie JL (2000) Collective efficacy versus self-efficacy in coping responses to stressors and control: A cross-cultural study. Journal of Applied Psychology 85: 512-525.

Schaufeli WB and Bakker AB (2004) Job demands, job resources, and their relationship with burnout and engagement: A multi-sample study. Journal of Organizational Behavior, 25: 293-315.

Shaffer MA and Harrison DA (1998) Expatriates' psychological withdrawal from international assignments: Work, nonwork, and family influences. Personnel Psychology 51: 87-118.

Shaffer MA and Harrison DA (2001) Forgotten partners of international assignments: Development and test of a model of spouse adjustment. Journal of Applied Psychology $86,238-254$.

Shaffer MA, Reiche BS, Dimitrova M, Lazarova M, Chen S, Westman M and Wurtz O (2016) Work-and family-role adjustment of different types of global professionals: Scale development and validation. Journal of International Business Studies 47: 113-139.

Siu OL, Lu CQ and Spector PE (2007) Employees' well-being in Greater China: The direct and moderating effects of general self-efficacy. Applied Psychology: An International Review 56: 288-301.

Takeuchi R (2010) A critical review of expatriate adjustment research through a multiple stakeholder view: Progress, emerging trends, and prospects. Journal of Management 36: 1040-1064. 
Takeuchi R, Yun S and Tesluk PE (2002) An examination of crossover and spillover effects of spousal and expatriate cross-cultural adjustment on expatriate outcomes. Journal of Applied Psychology 87: 655-666.

ten Brummelhuis L and Bakker A (2012) A resource perspective on the work-home resource model: The work-home resources model. American Psychologist 67: 545-556.

Tharenou P (2015) Researching expatriate types: The quest for rigorous methodological approaches. Human Resource Management Journal 25: 149-165.

Thompson MJ, Carlson DS and Kacmar KM (2021) Family matters: The impact of family functioning on co-worker outcomes. Human Relations 74: 1504-1531.

Wang M and Takeuchi R (2007) The role of goal orientation during expatriation: A crosssectional and longitudinal investigation. Journal of Applied Psychology 92: 14371445.

Westman M (2001) Stress and strain crossover. Human Relations 54: 557-591.

Westman M, Etzion D and Chen S (2009) The crossover of exhaustion and vigor between international business travelers and their spouses. Journal of Managerial Psychology 24: $269-284$.

Wu W-Y and Bodigerel-Koehler M (2013) The mediating effects of cross-cultural dynamic competencies on the relationship between multicultural personality and cross-cultural adjustment. International Journal of Human Resource Management 24: 4026-4045.

\section{Biographies}

B. Sebastian Reiche is a Professor of People Management at IESE Business School in Barcelona, Spain. His research focuses on the forms, prerequisites and consequences of global work, international HRM, global leadership and knowledge transfer. His work has appeared in Academy of Management Discoveries, Academy of Management Journal, 
Journal of International Business Studies, Journal of Management Studies, Organization Science and Personnel Psychology, among others. He is associate editor of Human Resource Management Journal, co-editor of Advances in Global Leadership, and regularly blogs on topics related to expatriation and global work (http://blog.iese.edu/expatriatus).

Mihaela Dimitrova is Assistant Professor at the Vienna University of Economics and Business, Austria. Her research interests center around global work experiences. In particular, her focus is on the management of global employees, cross-cultural management as well as employees' proactive behavior and thriving in international environments. Her work has appeared in the Journal of International Business Studies, Journal of Organizational Behavior, and Journal of World Business among others. [Email: mdimitro@wu.ac.at]

Mina Westman is a Professor (Emerita) of Organizational Behavior at Coller School of Management, Tel Aviv University, Israel. Her research focuses on forms of stress, crossover of negative and positive experiences in the family and at the workplace, crossover from leaders to followers, expatriation and respite. Her work has appeared in Annual Review of Organizational Psychology and Organizational Behavior, Academy of Management Journal, Journal of Management, Human Relations, Journal of Applied Psychology, among many others. She was an associate editor of Stress \& Health Journal.

Shoshi Chen is a faculty member in the Organizational Behavior department at Tel Aviv University's Coller School of Management. She received her Ph.D. in Organizational Behavior from the Faculty of Management at Tel-Aviv University, Israel. Over the years, she has consulted many organizations, developing and presenting executive programs including 
personal consulting. Her primary research interests are positive psychology and learning in organizations.

Olivier Wurtz is an Assistant Professor of Management at the University of Vaasa, Finland. He received his Ph.D. at HEC Paris. His current research interests include global work experiences, well-being, diversity and cross-cultural management. His work has been published in the Journal of International Business Studies and Journal of Management Studies, among others.

Mila Lazarova is the Canada Research Chair in Global Workforce Management and a Professor of International Business at the Beedie School of Business, Simon Fraser University (Canada). Her research interests include global careers, organizational career development and mobility practices in organizations; repatriation and career impact of global mobility; and HR issues related to workplace integration of skilled migrants. Her work has appeared in journals such as the Academy of Management Review, Journal of International Business Studies, Journal of World Business, Organizational Science, and Journal of Organizational Behavior, among others. Mila is currently a Consulting Editor at the Journal of World Business and sits on several other editorial boards.

Margaret A. Shaffer is the Michael F. Price Chair of International Business at the Price College of Business, The University of Oklahoma. Her research interests are in the areas of global mobility, expatriation, and work-life interplay. Her publications have appeared in the Academy of Management Review, Academy of Management Journal, Journal of Applied Psychology, Personnel Psychology, Journal of Management, and Journal of International 
Business Studies. She is an associate editor for the Journal of Global Mobility and serves on several editorial boards. 
Table 1. Means, standard deviations, internal consistency reliabilities, and correlations for study variables.

\begin{tabular}{|c|c|c|c|c|c|c|c|c|c|c|}
\hline Variable & Mean & $S D$ & 1 & 2 & 3 & 4 & 5 & 6 & 7 & 8 \\
\hline 1. Expatriate work role engagement (attention) (T2) & 6.08 & .94 & $(.90)$ & & & & & & & \\
\hline 2. Expatriate work role engagement (absorption) (T2) & 5.05 & 1.24 & .50 & $(.92)$ & & & & & & \\
\hline 3. Expatriate family role engagement (attention) (T2) & 4.97 & 1.34 & -.04 & -.02 & $(.91)$ & & & & & \\
\hline 4. Expatriate family role engagement (absorption) (T2) & 4.41 & 1.46 & -.05 & .27 & .52 & $(.93)$ & & & & \\
\hline 5. Expatriate family role adjustment & 3.59 & .86 & -.06 & -.09 & .40 & .27 & $(.88)$ & & & \\
\hline 6. Partner family role adjustment & 3.97 & .73 & .01 & .08 & .20 & .10 & .34 & $(.83)$ & & \\
\hline 7. Expatriate general self-efficacy & 4.07 & .58 & .08 & .29 & .21 & .32 & .31 & .19 & $(.91)$ & \\
\hline 8. Expatriate work role engagement (attention) (T1) & 6.30 & .75 & .71 & .56 & -.03 & .09 & -.01 & .09 & .28 & $(.88)$ \\
\hline 9. Expatriate work role engagement (absorption) (T1) & 4.92 & 1.18 & .34 & .71 & -.06 & .26 & -.04 & .20 & .34 & .50 \\
\hline 10. Expatriate family role engagement (attention) (T1) & 4.94 & 1.26 & -.14 & -.16 & .58 & .37 & .36 & .16 & .23 & -.04 \\
\hline 11. Expatriate family role engagement (absorption) (T1) & 4.37 & 1.52 & -.18 & .12 & .35 & .67 & .22 & .07 & .24 & -.09 \\
\hline 12. Expatriate cultural adjustment & 3.30 & .93 & .01 & -.16 & .19 & .05 & .35 & .06 & .03 & -.03 \\
\hline 13. Partner employment & .36 & .48 & -.03 & .02 & .24 & .18 & -.04 & .07 & .08 & -.05 \\
\hline 14. Expatriate gender & .21 & .41 & .27 & .29 & -.03 & .11 & -.11 & .07 & .11 & .30 \\
\hline 15. Expatriate age & 44.21 & 8.91 & .14 & -.01 & -.15 & -.28 & .10 & .04 & -.20 & .06 \\
\hline 16. Expatriate type & .62 & .49 & -.02 & .02 & .04 & .24 & .14 & .01 & .14 & .01 \\
\hline 17. Assignment duration ${ }^{a}$ & 2.38 & 2.81 & .05 & -.02 & .06 & .09 & .19 & -.03 & .09 & -.01 \\
\hline 18. Accompanying family members ${ }^{a}$ & 2.01 & 1.24 & -.07 & -.09 & .07 & .09 & .12 & .11 & .07 & -.02 \\
\hline
\end{tabular}

Note. $N=105$. All correlations with absolute value larger than .19 are significant at $p<.05$ and all correlations larger than .25 are significant at $p<$ .01 .

Internal consistency reliabilities are in parentheses on the diagonal. Expatriate gender $(0=$ male, $1=$ female $)$, expatriate age (years), partner employment $(0=$ currently unemployed, $1=$ currently employed $)$, expatriate type $(0=$ diplomats, $1=$ corporate and self-initiated expatriates $)$. $\mathrm{T} 1=$ Time 1 data collection; $\mathrm{T} 2$ = Time 2 data collection

${ }^{a}$ Variables not used in the final analysis. 
Table 1. Continued.

\begin{tabular}{|c|c|c|c|c|c|c|c|c|c|}
\hline Variable & 9 & 10 & 11 & 12 & 13 & 14 & 15 & 16 & 17 \\
\hline \multicolumn{10}{|l|}{ 1. Expatriate work role engagement (attention) (T2) } \\
\hline \multicolumn{10}{|l|}{ 2. Expatriate work role engagement (absorption) (T2) } \\
\hline \multicolumn{10}{|l|}{ 3. Expatriate family role engagement (attention) (T2) } \\
\hline \multicolumn{10}{|l|}{ 4. Expatriate family role engagement (absorption) (T2) } \\
\hline \multicolumn{10}{|l|}{ 5. Expatriate family role adjustment } \\
\hline \multicolumn{10}{|l|}{ 6. Partner family role adjustment } \\
\hline \multicolumn{10}{|l|}{ 7. Expatriate general self-efficacy } \\
\hline \multicolumn{10}{|l|}{ 8. Expatriate work role engagement (attention) (T1) } \\
\hline 9. Expatriate work role engagement (absorption) (T1) & $(.85)$ & & & & & & & & \\
\hline 10. Expatriate family role engagement (attention) (T1) & -.10 & $(.83)$ & & & & & & & \\
\hline 11. Expatriate family role engagement (absorption) (T1) & .10 & .53 & $(.93)$ & & & & & & \\
\hline 12. Expatriate cultural adjustment & -.10 & .13 & .06 & $(.87)$ & & & & & \\
\hline 13. Partner employment & -.01 & .26 & .11 & .07 & - & & & & \\
\hline 14. Expatriate gender & .33 & -.10 & .10 & -.11 & .08 & - & & & \\
\hline 15. Expatriate age & -.03 & -.19 & -.33 & .15 & -.16 & -.23 & - & & \\
\hline 16. Expatriate type & -.03 & .01 & .12 & .05 & -.13 & -.42 & .09 & - & \\
\hline 17. Assignment duration ${ }^{a}$ & -.01 & .01 & .06 & .30 & .14 & -.14 & .13 & .22 & - \\
\hline 18. Accompanying family members ${ }^{\text {a }}$ & -.08 & .19 & .13 & .05 & -.02 & -.14 & -.11 & .12 & .07 \\
\hline
\end{tabular}

Note. $N=105$. All correlations with absolute value larger than .19 are significant at $p<.05$ and all correlations larger than .25 are significant at $p<$ .01 .

Internal consistency reliabilities are in parentheses on the diagonal. Expatriate gender $(0=$ male, $1=$ female), expatriate age (years), partner employment $(0=$ currently unemployed, $1=$ currently employed $)$, expatriate type $(0=$ diplomats, $1=$ corporate and self-initiated expatriates $)$. $\mathrm{T} 1$ = Time 1 data collection; $\mathrm{T} 2$ = Time 2 data collection

${ }^{\mathrm{a}}$ Variables not used in the final analysis. 
Table 2. Ordinary least squares regression (Hypotheses 1 and 2).

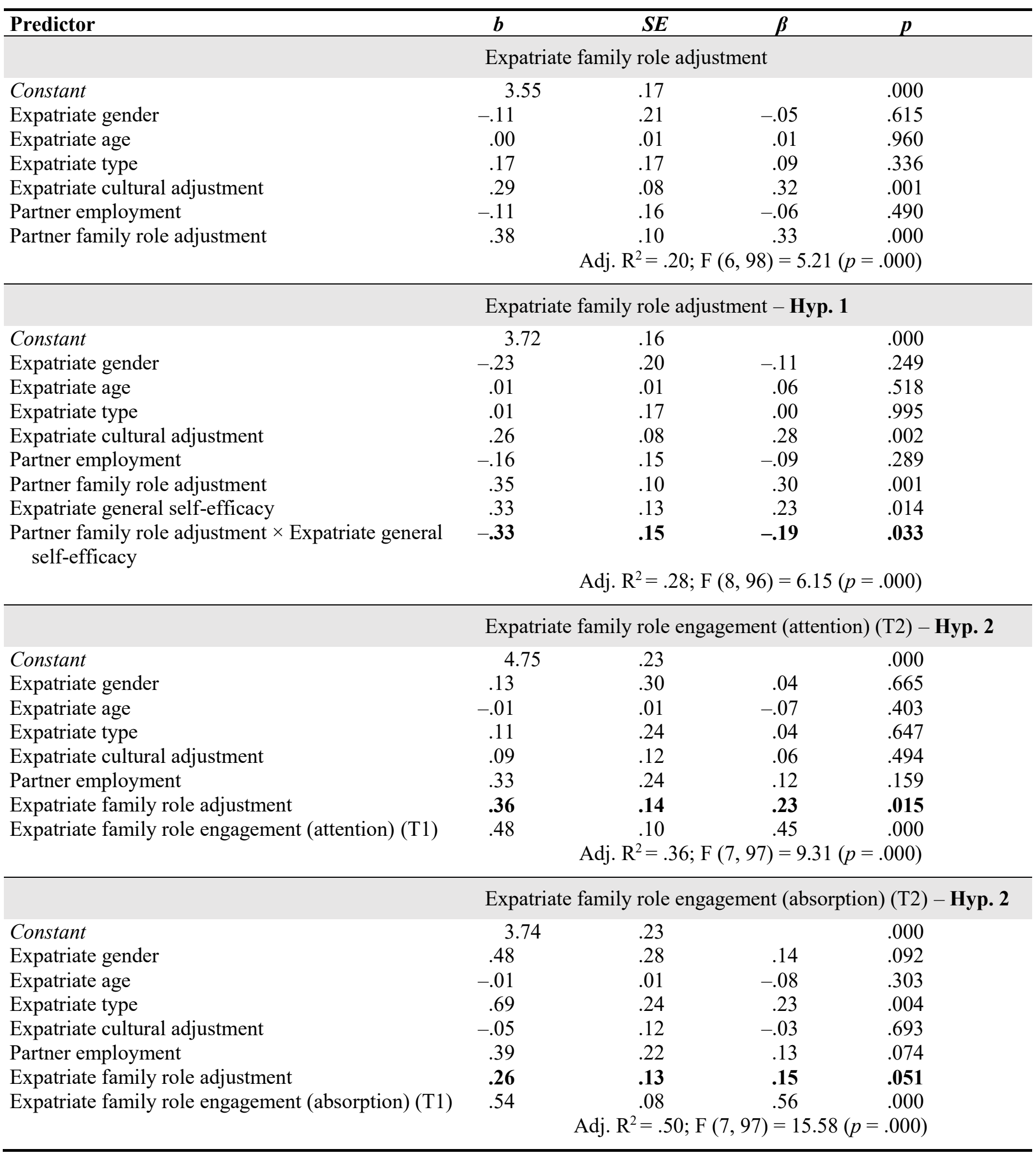

Note. $N=105$. Table presents unstandardized estimates $(b)$ with their respective standard error $(S E)$, standardized coefficient $(\beta)$, and $p$-value $(p)$.

$\mathrm{T} 1=$ Time $1 ; \mathrm{T} 2=$ Time 2 . 
Table 3. Ordinary least squares regression (Hypothesis 4).

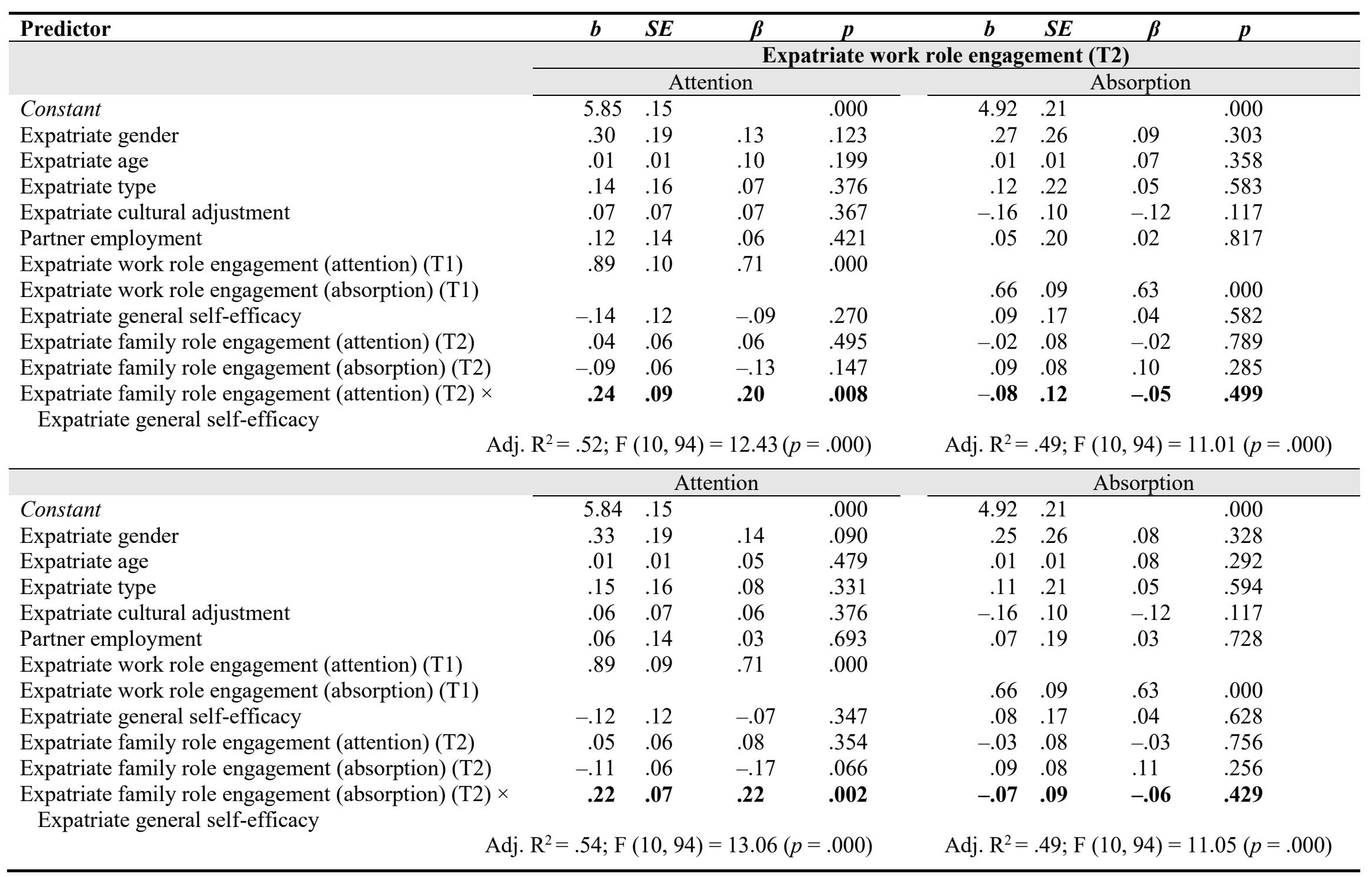

Note. $N=105$. Table presents unstandardized estimates $(b)$ with their respective standard error $(S E)$, standardized coefficient $(\beta)$, and $p$-value $(p)$. T1 $=$ Time 1 ; T2 $=$ Time 2 . 
Figure 1. Theoretical model

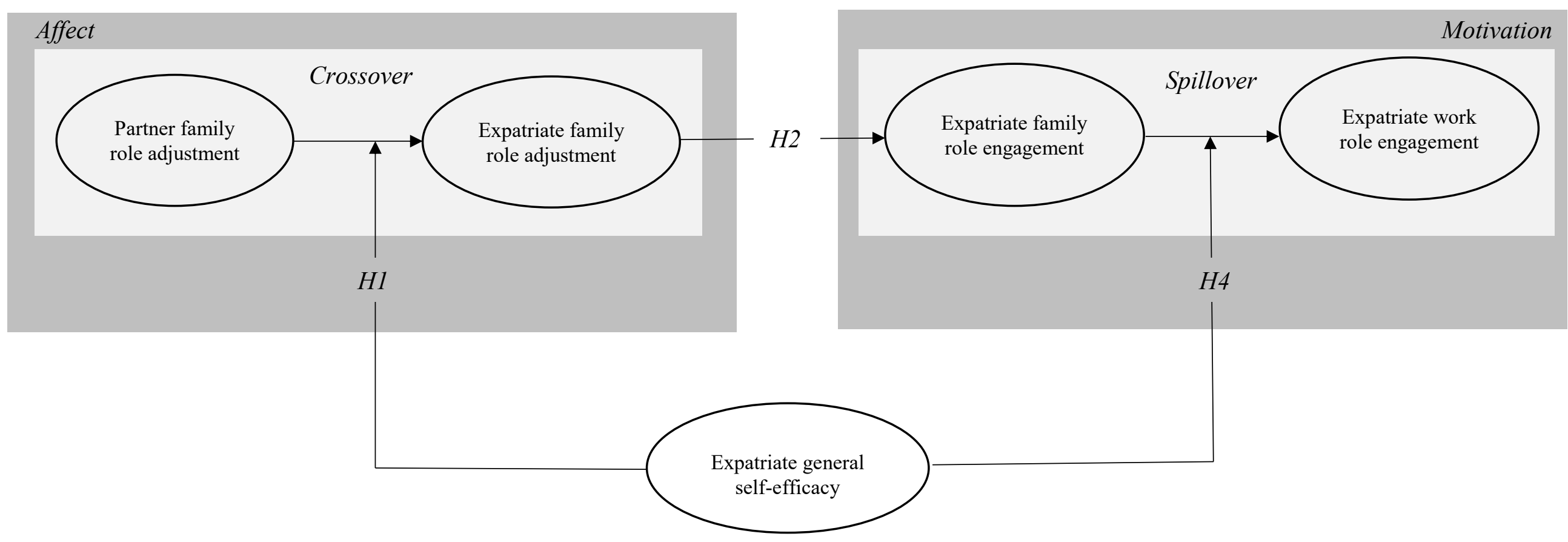

Note. H1, 2, and 4 represent the corresponding hypotheses. Not shown in this model are H3, which represents the moderated indirect effect of partner family role adjustment on expatriate family role engagement, and $\mathrm{H} 5$, which refers to the moderated indirect effect of expatriate family role adjustment on expatriate work role engagement. 
Figure 2. Expatriate general self-efficacy as moderator of crossover.

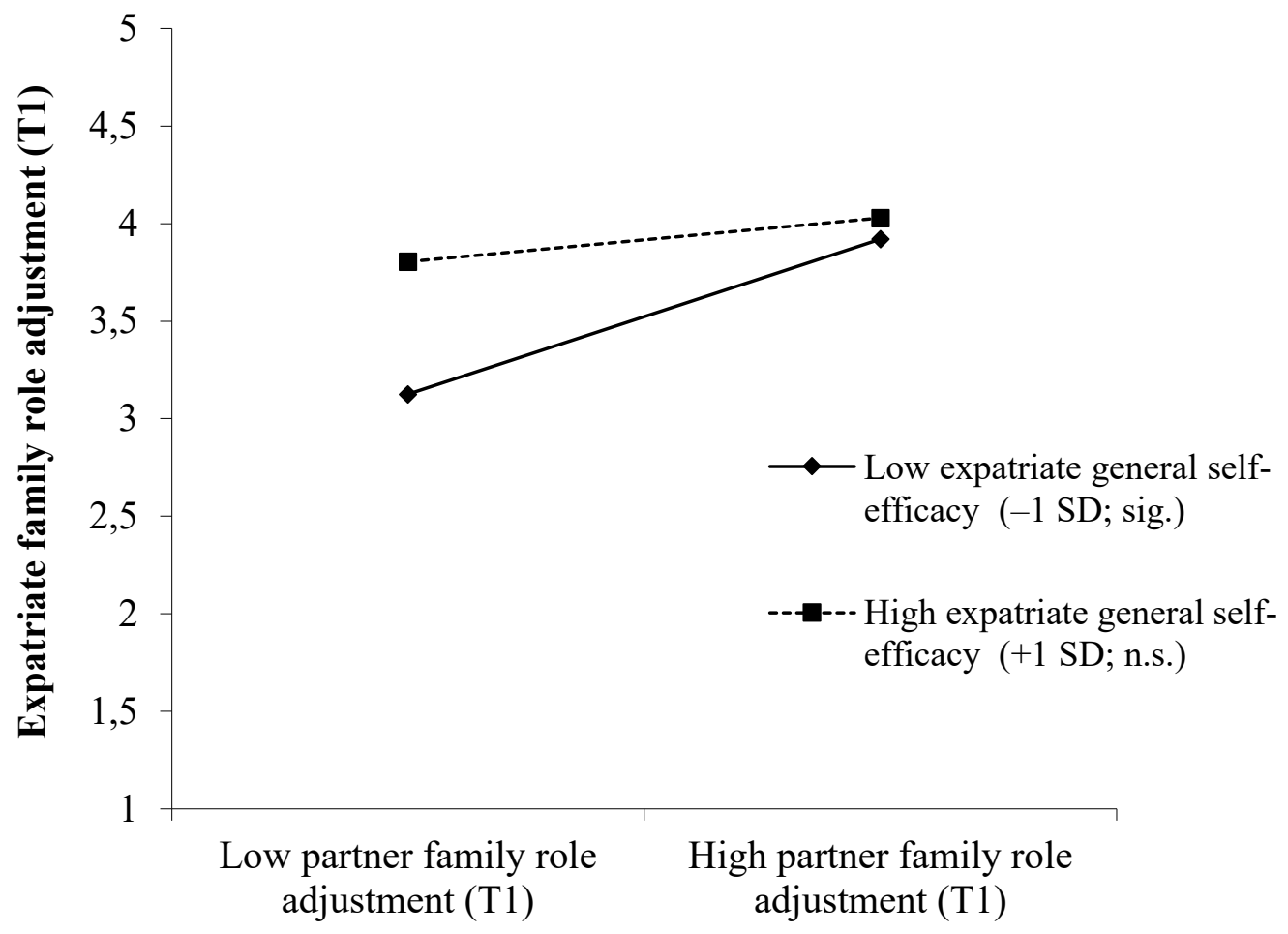


Figure 3. Expatriate general self-efficacy as moderator of spillover.
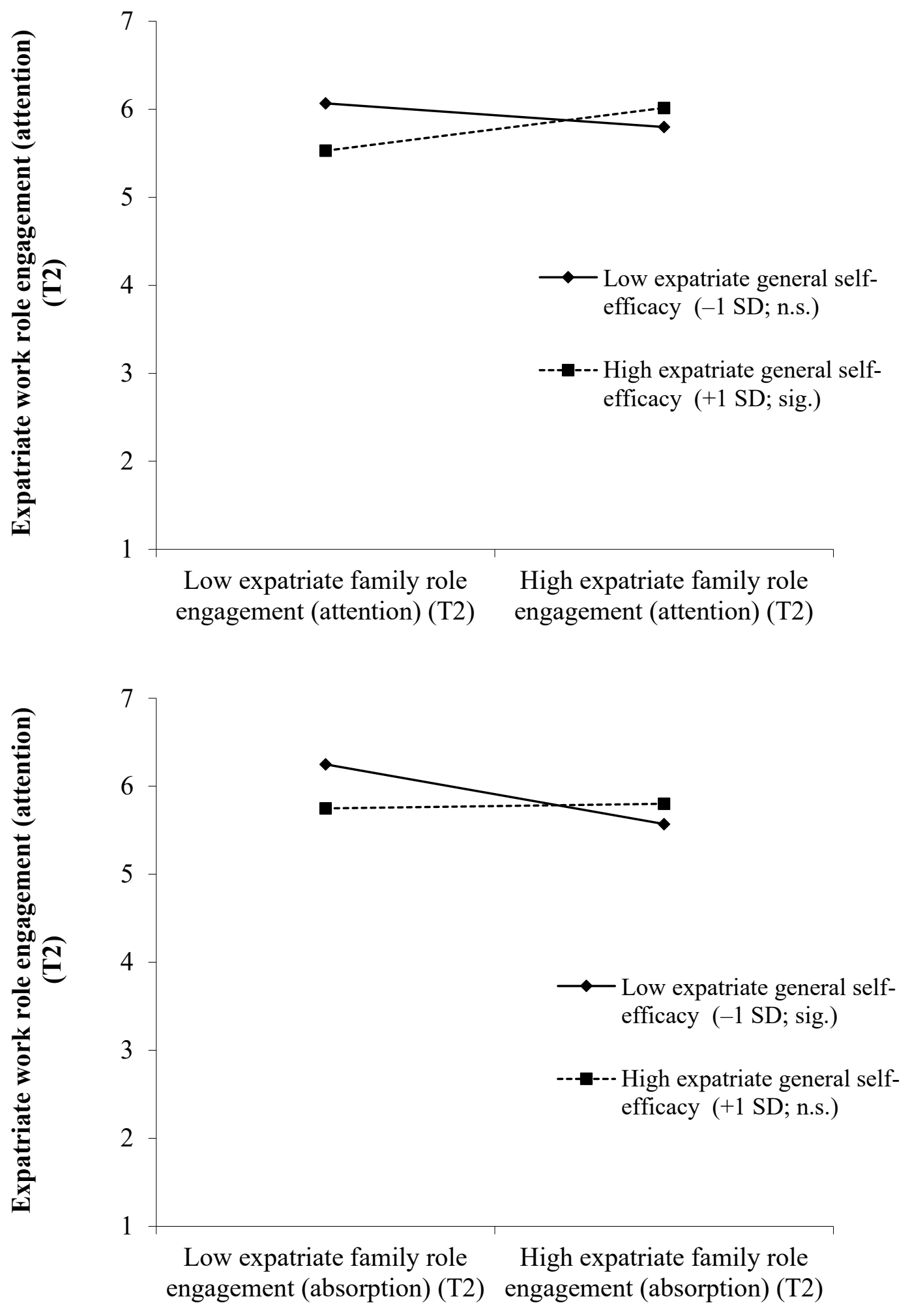